\title{
Bench Assessment of a New Insufflation-Exsufflation Device
}

\author{
Véronique Porot MD and Claude Guérin MD PhD
}

\begin{abstract}
BACKGROUND: The Nippy Clearway is a new mechanical insufflation-exsufflation device used to assist cough. METHODS: We compared the peak expiratory flow (PEF) with the Nippy Clearway versus the CoughAssist in a bench experiment. The relationship between PEF and pressure at the airway opening during exsufflation (minimum expiratory $\mathbf{P}_{\mathrm{AO}}$ ) was investigated under 6 combinations of compliance (30 or $\left.60 \mathrm{~mL} / \mathrm{cm} \mathrm{H}_{2} \mathrm{O}\right)(\mathrm{C} 30$ and $\mathrm{C60})$ and resistance $(0,5$, or $20 \mathrm{~cm} \mathrm{H}$ (R0, R5, and R20) over a $25-50 \mathrm{~cm} \mathrm{H} \mathrm{H}_{2} \mathrm{O}$ range of set $\mathrm{P}_{\mathrm{AO}}$. The intercepts and slopes of the linear regression performed over PEF and $\mathrm{P}_{\mathrm{AO}}$ relationships were compared for both devices. RESULTS: For the C30R0, C30R5, and C60R5 conditions, the change in both the intercepts and slopes was significant with the Nippy Clearway, compared to the CoughAssist, averaging $-2.96 \mathrm{~L} / \mathrm{s}$ and $-0.03 \mathrm{~L} / \mathrm{s} / \mathrm{cm} \mathrm{H}_{2} \mathrm{O},-1.46 \mathrm{~L} / \mathrm{s}$ and $0.02 \mathrm{~L} / \mathrm{s} / \mathrm{cm} \mathrm{H}_{2} \mathrm{O}$, and $-1.02 \mathrm{~L} / \mathrm{s}$ and $-0.04 \mathrm{~L} / \mathrm{s} / \mathrm{cm} \mathrm{H}_{2} \mathrm{O}$, respectively. As a result, at any minimum expiratory $P_{A O}$, PEF was significantly greater with the Nippy Clearway. For C30R20 and C60R20, the regression lines were similar for the Nippy Clearway and CoughAssist. CONCLUSIONS: In this bench study, PEF with the Nippy Clearway was greater than with the CoughAssist at low respiratory-system compliance. Key words: airway clearance; secretion clearance; mechanical insufflation-exsufflation; cough. [Respir Care 2013;58(9):1536-1540. (C) 2013 Daedalus Enterprises]
\end{abstract}

\section{Introduction}

Increasing cough efficacy using dedicated mechanical devices is the main therapeutic goal in various clinical conditions with cough impairment, such as chronic neuromuscular weakness ${ }^{1-3}$ or critical illness neuromyopathy. In France, the CoughAssist (Philips Respironics, Murrysville, Pennsylvania) is the reference device for cough enhancement. The Nippy Clearway (B\&D Electromedical, Stratford-Upon-Avon, Warwickshire, United Kingdom) is a recently released mechanical insufflation-exsufflation device with several new features. The aim of this study was to assess the Nippy Clearway's ability to generate peak expiratory flow (PEF). We selected PEF as the main

The authors are affiliated with Service de Réanimation Médicale, Hôpital de la Croix-Rousse, Hospices Civils de Lyon, Université de Lyon, Lyon, France.

The authors have disclosed no conflicts of interest.

Correspondence: Claude Guérin MD PhD, Service de Réanimation Médicale, Hôpital de la Croix Rousse, 103 Grande Rue de la Croix Rousse, 69004 Lyon, France. E-mail: claude.guerin@chu-lyon.fr.

DOI: $10.4187 /$ respcare. 02345 end point because it is the primary determinant of cough efficacy and hence of airway secretion clearance. We performed a bench study to compare the Nippy Clearway to the CoughAssist. Our hypothesis was that PEF would be higher with the Nippy Clearway because of its more advanced technology.

\section{Methods}

We tested a new Nippy Clearway and a new Cough Assist, both fully checked by their manufacturers prior to the study. We used a 2-lung configuration test lung (TTL, Michigan Instruments, Grand Rapids, Michigan) with adjustable compliance and resistance. The data acquisition system included a pneumotachograph (3830/4830, Hans Rudolph, Shawnee, Kansas) with a straight connector (VBM Medizintechnik, Sulz, Germany) to measure pressure at the airway opening $\left(\mathrm{P}_{\mathrm{AO}}\right)$. The pneumotachograph was linear over a flow range of $\pm 10 \mathrm{~L} / \mathrm{s}$. The flow and $\mathrm{P}_{\mathrm{AO}}$ ports were connected to piezoresistive transducers (BD Gabarith, Vogt Medical Vertrieb, Karlsruhe, Germany). The signals were amplified, sent to an analog-todigital converter (MP150, Biopac Systems, Goleta, California), and recorded at $400 \mathrm{~Hz}$ (Acqknowledge, Biopac Systems, Goleta, California). 


\section{Protocol}

The experiment was performed over the course of one day in our laboratory, within our medical ICU, at room temperature and in room air. Before the experiment the piezoresistive transducers were calibrated with a rotameter flow meter (Martin Médical, Lyon, France) and a manometer (Fluke Electronics, Everett, Washington).

The test lung was used in its single-lung configuration. The device was attached to the pneumotachograph and $\mathrm{P}_{\mathrm{AO}}$ port, which was connected to the test lung. Two levels of compliance ( 30 and $\left.60 \mathrm{~mL} / \mathrm{cm} \mathrm{H}_{2} \mathrm{O}\right)(\mathrm{C} 30$ and $\mathrm{C} 60)$ and 3 levels of resistance $\left(0,5\right.$, and $\left.20 \mathrm{~cm} \mathrm{H}_{2} \mathrm{O} / \mathrm{L} / \mathrm{s}\right)(\mathrm{R} 0, \mathrm{R} 5$, and R20) were tested in random order. Both devices were set to automatic mode. The inspiratory time was $3 \mathrm{sec}-$ onds, the expiratory time was 1 second, and there was 1 -second pause after expiration.

A 1-min stabilization period was allowed before each stage, after which a series of pressure pairs (positive then negative) was delivered. The pressures used ranged between $-25 /+25 \mathrm{~cm} \mathrm{H}_{2} \mathrm{O}$ and $-50 /+50 \mathrm{~cm} \mathrm{H}_{2} \mathrm{O}$, by steps of $5 \mathrm{~cm} \mathrm{H}_{2} \mathrm{O}$ for each device. For each pressure pair level, 10 consecutive breaths were recorded, and the last 3 were retained for analysis.

\section{Data Analysis}

The experiment generated 6 compliance/resistance combinations, with 6 pressure pairs and 3 repetitions each, making a total of 108 measurements. The main outcome was PEF, taken as the lowest negative PEF, without taking into account any artifacts (Fig. 1). We measured actual $\mathrm{P}_{\mathrm{AO}}$, and used a linear regression analysis to model the relationship of PEF to minimum expiratory $\mathrm{P}_{\mathrm{AO}}$, which was the lowest negative $\mathrm{P}_{\mathrm{AO}}$ (see Fig. 1). Each condition was analyzed separately to test the effects of the device and the artificial airways in different mechanical conditions representing different respiratory mechanics. Each model was supplied with estimates of 2 parameters: intercept and slope. A reduction in slope between the devices indicates a smaller PEF decrease for the same change in minimum expiratory $\mathrm{P}_{\mathrm{AO}}$. The changes in the intercepts and slopes were analyzed with statistics software (R 2.9.0, R Foundation, Vienna, Austria). The estimates of the slopes and intercepts are expressed as mean \pm SD. The coefficient of determination $\left(\mathrm{R}^{2}\right)$ was used in the regression analysis. $P<.05$ was set as the threshold for statistical significance.

\section{Results}

For C30R0 and C30R5 the intercepts were significantly lower and the slopes significantly steeper with Nippy Clearway than with CoughAssist (Table 1), so, at any minimum expiratory $\mathrm{P}_{\mathrm{AO}}$, $\mathrm{PEF}$ was significantly greater (ie, more

\section{QUICK LOOK}

\section{Current knowledge}

Mechanical insufflation-exsufflation is effective for airway secretion clearance in patients with neuromuscular disease. Maximizing the effectiveness of insufflationexsufflation requires maximizing the peak expiratory flow.

\section{What this paper contributes to our knowledge}

In a lung model study, with the lower compliance setting $\left(30 \mathrm{~mL} / \mathrm{cm} \mathrm{H}_{2} \mathrm{O}\right)$ the Nippy Clearway insufflationexsufflation device created a higher peak expiratory flow than the CoughAssist insufflation-exsufflation device. The clinical meaning of these findings remains to be determined.

negative) with Nippy Clearway (Fig. 2). The same significant differences in intercept and slope between the 2 devices were found for C60R5 as for C30R0 and C30R5 (see Table 1). At C60R5 the CoughAssist did not reach a minimum expiratory $\mathrm{P}_{\mathrm{AO}}$ lower than $35 \mathrm{~cm} \mathrm{H}_{2} \mathrm{O}$ (see Fig. 2), so PEF was not directly measured with CoughAssist below $35 \mathrm{~cm} \mathrm{H}_{2} \mathrm{O}$, and no comparison can be made between the devices.

The results regarding C60R0 were similar to those obtained for C30R0 and C30R5, except for a nonsignificant change in slope (see Table 1). The PEF values were, however, markedly greater with Nippy Clearway than with CoughAssist at all the minimum expiratory $\mathrm{P}_{\mathrm{AO}}$ investigated (see Fig. 2). At C30R20 the intercept and slope did not differ between devices (see Table 1) and the PEF values were similar at any minimum expiratory $\mathrm{P}_{\mathrm{AO}}$ (see Fig. 2). Finally, at C60R20 the slope, but not the intercept, was significantly steeper with Nippy Clearway than with CoughAssist (see Table 1), resulting in a marginal and probably clinically irrelevant PEF difference between the devices (see Fig. 2).

\section{Discussion}

PEF was greater with Nippy Clearway than with CoughAssist. Cough is the main component of airway clearance. ${ }^{4}$ Cough efficiency is related to peak cough flow, so peak cough flow is an objective measure of cough efficacy. In patients with neuromuscular disease and weak cough, airway secretion clearance is impaired. Cough efficiency must therefore be improved in these patients, and this can be achieved using various methods. However, the resulting PEF differs according to the choice of method. Manually assisted peak cough flow is greater than unassisted peak cough flow, and peak cough flow can be fur- 

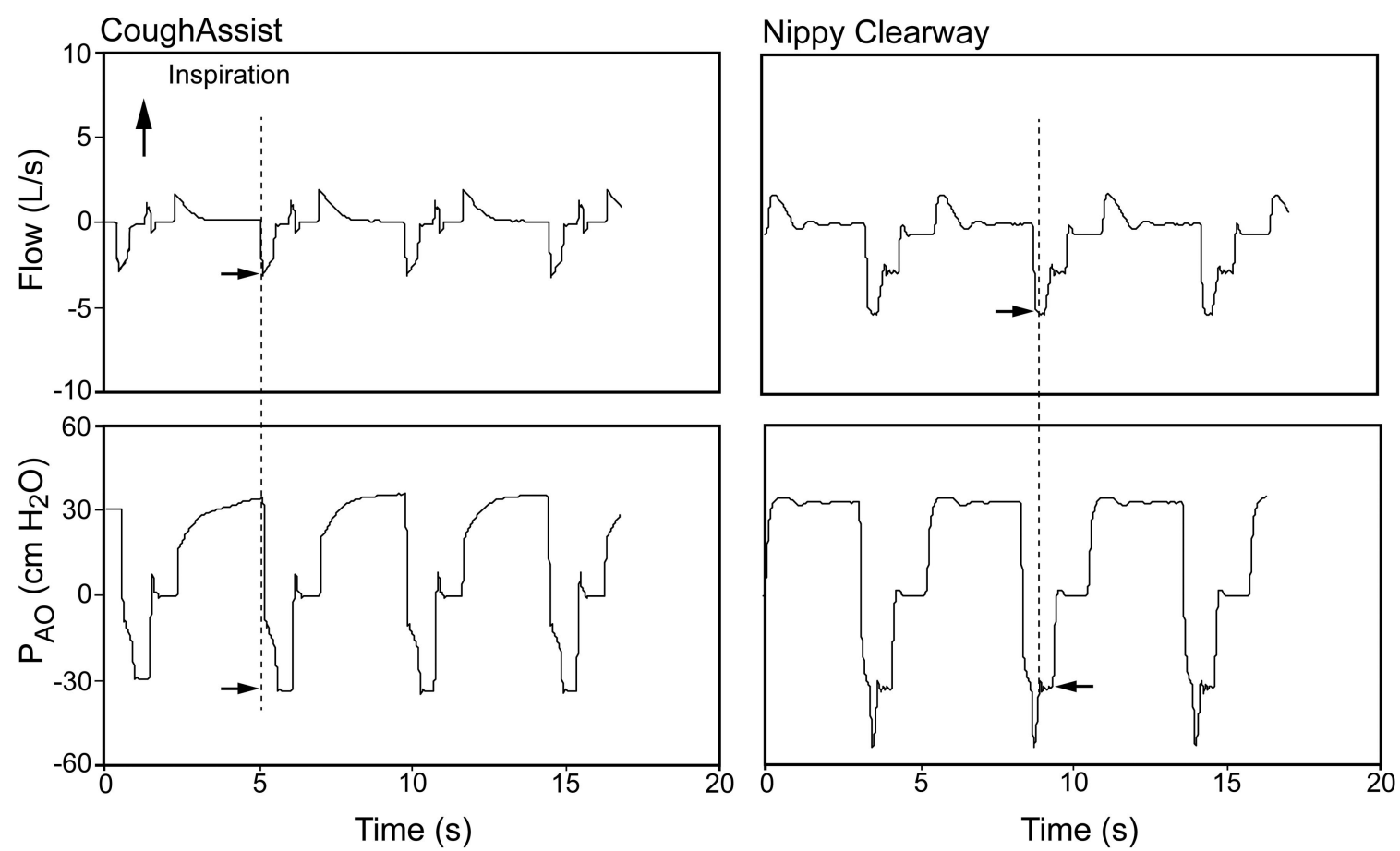

Fig. 1. Flow and pressure at the airway opening $\left(\mathrm{P}_{\mathrm{AO}}\right)$ versus time, with lung-model compliance set at $30 \mathrm{~mL} / \mathrm{cm} \mathrm{H}_{2} \mathrm{O}$ and resistance set at $5 \mathrm{~cm} \mathrm{H} \mathrm{H}_{2} \mathrm{O} / \mathrm{L} / \mathrm{s}$. The dotted vertical lines and horizontal arrows indicate the moments of peak expiratory flow and minimum expiratory pressure. The vertical arrow indicates the flow direction of inspiration.

Table 1. Change in Intercepts and Slopes in the Linear Regression Analysis for the Nippy Clearway From the Reference CoughAssist Between Peak Expiratory Flow and Pressure at the Airway Opening

\begin{tabular}{|c|c|c|c|c|}
\hline & $\begin{array}{l}\text { Change in Intercept } \\
\text { mean } \pm \mathrm{SE} \mathrm{L/s*}\end{array}$ & $\begin{array}{c}\text { Change in Slope } \\
\text { mean } \pm \mathrm{SE} \\
\mathrm{L} / \mathrm{s} / \mathrm{cm} \mathrm{H}_{2} \mathrm{O}\end{array}$ & $\begin{array}{c}P \text { for } \\
\text { Change in Intercept }\end{array}$ & $\begin{array}{c}P \text { for } \\
\text { Change in Slope }\end{array}$ \\
\hline $\begin{array}{l}\text { Compliance } 30 \\
\text { Resistance } 0\end{array}$ & $-2.96 \pm 0.13$ & $-0.03 \pm 0.004$ & $<.001$ & $<.001$ \\
\hline $\begin{array}{l}\text { Compliance } 30 \\
\text { Resistance } 5\end{array}$ & $-1.46 \pm 0.22$ & $0.02 \pm 0.008$ & $<.001$ & .04 \\
\hline $\begin{array}{l}\text { Compliance } 30 \\
\text { Resistance } 20\end{array}$ & $-0.34 \pm 0.35$ & $-0.005 \pm 0.01$ & .34 & .64 \\
\hline $\begin{array}{l}\text { Compliance } 60 \\
\text { Resistance } 0\end{array}$ & $-1.83 \pm 0.28$ & $0.002 \pm 0.008$ & $<.001$ & .84 \\
\hline $\begin{array}{l}\text { Compliance } 60 \\
\text { Resistance } 5\end{array}$ & $-1.02 \pm 0.27$ & $-0.04 \pm 0.01$ & $<.001$ & $<.001$ \\
\hline $\begin{array}{l}\text { Compliance } 60 \\
\text { Resistance } 20\end{array}$ & $-0.12 \pm 0.10$ & $-0.01 \pm 0.004$ & .24 & .001 \\
\hline
\end{tabular}

ther enhanced using the breath-stacking method, ${ }^{5}$ which takes advantage of the increased lung capacity to increase peak cough flow.

The highest peak cough flow values, however, are obtained with insufflation-exsufflation devices. In patients with neuromuscular disease, Chatwin et $\mathrm{al}^{1}$ found that unassisted peak cough flow averaged $2.81 \mathrm{~L} / \mathrm{s}$, and that peak cough flow reached $3.00 \mathrm{~L} / \mathrm{s}$ with physiotherapy, $3.00 \mathrm{~L} / \mathrm{s}$ with noninvasive ventilation, $3.92 \mathrm{~L} / \mathrm{s}$ with exsufflation assistance, and $4.95 \mathrm{~L} / \mathrm{s}$ with insufflation-exsufflation mechanical assistance. In normal subjects in the same study, ${ }^{1}$ unassisted peak cough flow averaged $9.63 \mathrm{~L} / \mathrm{s}$, and significantly increased to $10.48 \mathrm{~L} / \mathrm{s}$ with insufflationexsufflation. These figures are important for several reasons. First, they provide a basis for defining a peak cough flow threshold to define the starting point for using cough 

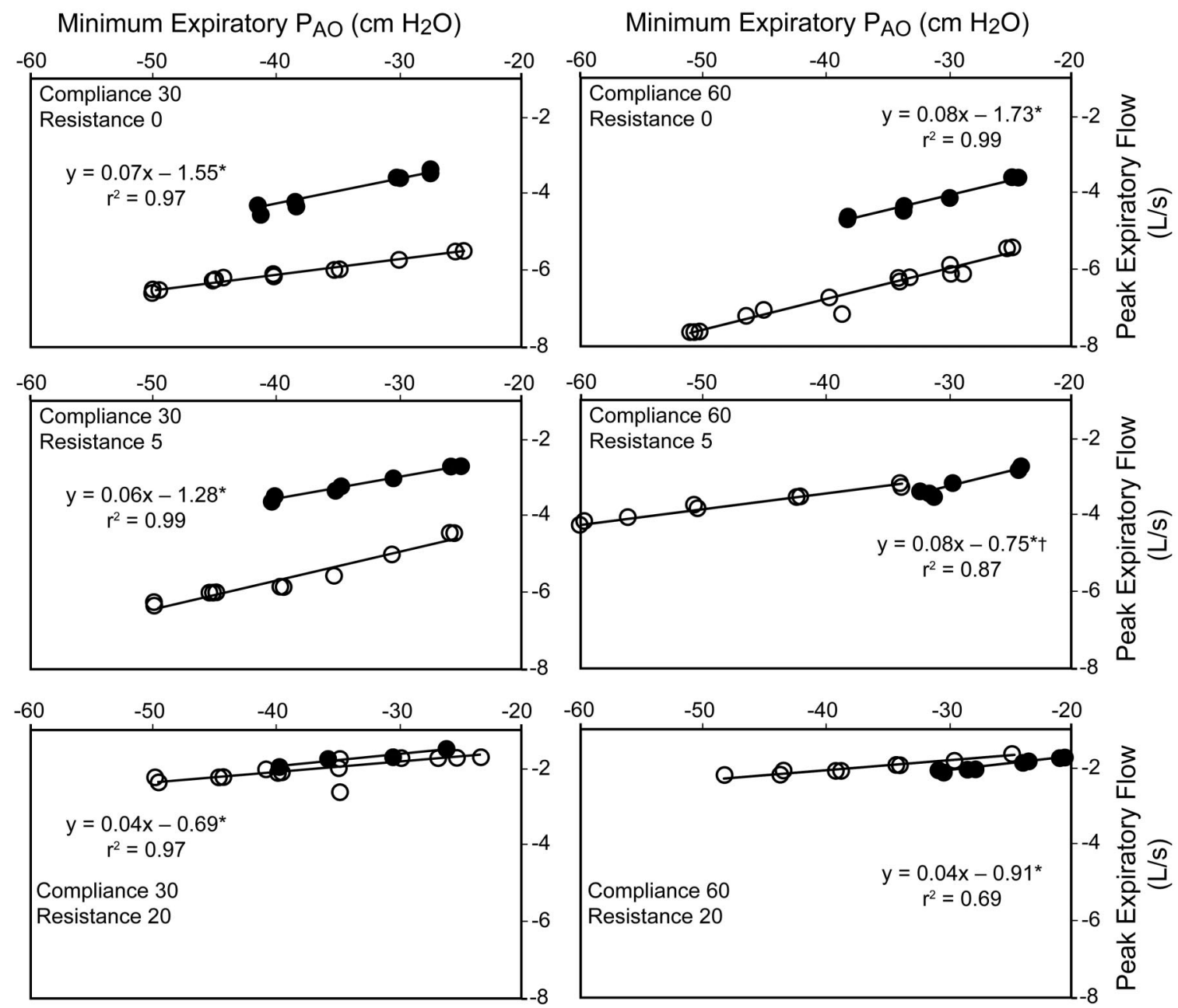

Fig. 2. Peak expiratory flow and minimum expiratory pressure at the airway opening $\left(\mathrm{P}_{\mathrm{AO}}\right)$ during exsufflation with CoughAssist (dots) and Nippy Clearway (circles) at set compliance of 30 or $60 \mathrm{~mL} / \mathrm{cm} \mathrm{H}_{2} \mathrm{O}\left(\mathrm{C} 30\right.$ and C60) and at set resistance of 0,5, or $20 \mathrm{~cm} \mathrm{H} \mathrm{H}_{2} \mathrm{O} / \mathrm{L} / \mathrm{s}(\mathrm{R} 0, \mathrm{R} 5$, R20). The lines are regression lines. The linear regression equations were for the CoughAssist, which was the reference device. ${ }^{*} P<.01$ versus 0 for intercept and slopes. $† P=.05$ versus 0 for intercept.

assistance. Second, they inform the clinician/researcher about which flow meter should be used to obtain an accurate measurement, as the flow meter's range of accuracy needs to match the PEF range investigated. Third, they help to quantify the efficacy of cough-enhancement interventions and, hence, to select the best one.

Table 2 shows the PEF values computed using the mean values of the intercepts and slopes in Table 1 and Figure 2 for minimum expiratory $\mathrm{P}_{\mathrm{AO}}$ of $40 \mathrm{~cm} \mathrm{H}_{2} \mathrm{O}$. This table shows that both devices are very sensitive to high resistance, as PEF markedly decreased at R20. At this high resistance, Nippy Clearway and CoughAssist exhibited virtually the same relationship between PEF and minimum expiratory $\mathrm{P}_{\mathrm{AO}}$ (see Fig. 2). Nippy Clearway was superior

Table 2. Mean Values of Peak Expiratory Flow Computed From the Mean Values of Intercepts and Slopes in Table 1 at Maximum Expiratory Pressure of $-40 \mathrm{~cm} \mathrm{H}_{2} \mathrm{O}$

\begin{tabular}{lcccccc}
\hline \hline & \multicolumn{4}{c}{ Peak Expiratory Flow, L/s } \\
\cline { 2 - 7 } & Compliance 30 & Compliance 30 & Compliance 30 & Compliance 60 & Compliance 60 & Compliance 60 \\
Resistance 5 & Resistance 20 \\
\hline Resistance 0 & Resistance 5 & Resistance 20 & Resince 0 & -3.95 & -2.51 \\
Nippy Clearway & -4.35 & -3.68 & -2.29 & -4.93 & -3.37 & -2.23 \\
\hline
\end{tabular}


to CoughAssist in terms of PEF under low compliance and resistance. In a previous bench study with a similar setup 6 we measured PEF generated with CoughAssist, and, compared to the results from that study, the present PEF values are $0.60 \mathrm{~L} / \mathrm{s}$ greater. It is likely that this difference comes from the use of a different device.

The difference in PEF between the Nippy Clearway and CoughAssist at low compliance and resistance can be explained by their technological features. The turbine in the CoughAssist works as an open circuit, and there is a time lag for the power to reach the set pressure. In contrast, the Nippy Clearway works as a closed circuit and is under pressure as soon as the machine is turned on. Pressure is delivered from the turbine by opening a valve. As seen in Figure 1, the shape of the inflation curve is quite different between the 2 devices: it increases abruptly and then remains constant with Nippy Clearway, but increases progressively with CoughAssist. Therefore, with the Nippy Clearway the set pressure is reached from the onset of inflation and maintained at that level, while with the CoughAssist the set pressure is reached at the very end. For a higher set pressure the flow increases with both devices. The flow increases further to overcome the increased resistance added to the setup. The set pressure is reached with Nippy Clearway but may not be achieved with CoughAssist.

In a previous study ${ }^{7}$ we found that the Alpha 200 adapted to higher set pressure and/or increased resistance by increasing the inflation time to reach the set pressure. Finally, the fact that the 2 devices in the present study exhibited a close relationship between PEF and minimum expiratory $\mathrm{P}_{\mathrm{AO}}$ at the highest resistance (R20) highlights the limitations of the power of the Nippy Clearway device.

\section{Clinical Implications}

In invasively ventilated patients with neuromuscular disease and who failed a spontaneous breathing trial, ${ }^{8}$ an assisted peak cough flow of $\geq 2.66 \mathrm{~L} / \mathrm{s}$ while intubated was associated with a $100 \%$ success rate for extubation. The post-extubation process in unweanable patients with neuromuscular disease included aggressive noninvasive ventilation and mechanical cough assistance, but a similar peak cough flow threshold predicted successful extubation in patients with neuromuscular disease in a previous study from the same group. ${ }^{9}$

From the data from Chatwin et al, ${ }^{1}$ compliance can be estimated at $35 \mathrm{~mL} / \mathrm{cm} \mathrm{H}_{2} \mathrm{O}$ across all patients. Comparing the PEF values found by Chatwin et $\mathrm{al}^{1}$ to those found in the present study, for similar compliance, shows that Nippy Clearway can improve airway clearance if the resistance is nil.

Insufflation-exsufflation shortens the duration of airway clearance sessions, ${ }^{2}$ which is an important benefit for patient quality of life. However, abruptly increasing PEF may be disadvantageous for patients with chronic air-flow obstruction and lower lung elastic recoil. Mucus clearance, measured by using radioactive tracers, increased significantly during forced expirations and coughing in patients with chronic bronchitis, but not in those with emphysema. ${ }^{10}$

\section{Limitations}

The main limitation of the present study is that it was in vitro; the results cannot be extrapolated to in vivo condition. However, the results should encourage in vivo investigation of the Nippy Clearway. The study used devices that are currently available on the market. Further developments in turbines and software are coming for both devices and may improve their performance.

\section{Conclusions}

The Nippy Clearway created higher PEF than the CoughAssist at low compliance. Clinical investigation of the Nippy Clearway is needed.

\section{REFERENCES}

1. Chatwin M, Ross E, Hart N, Nickol AH, Polkey MI, Simonds AK. Cough augmentation with mechanical insufflation/exsufflation in patients with neuromuscular weakness. Eur Respir J 2003;21(3): 502-508.

2. Chatwin M, Simonds AK. The addition of mechanical insufflation/exsufflation shortens airway-clearance sessions in neuromuscular patients with chest infection. Respir Care 2009;54(11): 1473-1479.

3. Gómez-Merino E, Bach JR. Duchenne muscular dystrophy: prolongation of life by noninvasive ventilation and mechanically assisted coughing. Am J Phys Med Rehabil 2002;81(6):411-415.

4. Homnick DN. Mechanical insufflation-exsufflation for airway mucus clearance. Respir Care 2007;52(10):1296-1305; discussion 1306-1307.

5. Toussaint M, Boitano LJ, Gathot V, Steens M, Soudon P. Limits of effective cough-augmentation techniques in patients with neuromuscular disease. Respir Care 2009;54(3):359-366.

6. Guérin C, Bourdin G, Leray V, Delannoy B, Bayle F, Germain M, Richard JC. Performance of the coughassist insufflation-exsufflation device in presence of endotracheal tube or tracheotomy tube: a bench study. Respir Care 2011;56(8):1108-1114.

7. Bourdin G, Guérin C, Leray V, Delannoy B, Debord S, Bayle F, Richard JC. Comparison of Alpha 200 and CoughAssist as intermittent positive pressure breathing devices: a bench study. Respir Care 2012;57(7):1129-1136.

8. Bach JR, Gonçalves MR, Hamdani I, Winck JC. Extubation of patients with neuromuscular weakness: a new management paradigm. Chest 2010;137(5):1033-1039.

9. Bach JR, Ishikawa Y, Kim H. Prevention of pulmonary morbidity for patients with Duchenne muscular dystrophy. Chest 1997;112(4): 1024-1028.

10. van der Schans CP, Piers DA, Beekhuis H, Koëter GH, van der Mark TW, Postma DS. Effect of forced expirations on mucus clearance in patients with chronic airflow obstruction: effect of lung recoil pressure. Thorax 1990;45(8):623-627. 